\title{
EL DERECHO A LA IDENTIDAD CULTURAL: UNA APROXIMACIÓN A LA INTEGRIDAD CULTURAL DE COMUNIDADES INDÍGENAS
}

\author{
ROBERTO LUIS BRAVO FIGUEROA ${ }^{1}$
}

RESUMEN: Este ensayo aborda la naturaleza jurídica del derecho a la identidad cultural y su importancia como un principio de interpretación que posibilita el debate sobre los alcances y el entendimiento que deben tener los derechos fundamentales en función del contexto cultural de los grupos indígenas. Se expone además que todo Estado comprometido con la diversidad cultural debe asumir como una finalidad legítima para su democracia, la preservación de las comunidades indígenas a través del reconocimiento de su integridad cultural como un derecho fundamental. Lo anterior, teniendo en cuenta que la preservación de la cultura es esencial para la supervivencia de las comunidades indígenas en tanto que funciona como un agente de auto adscripción que permite a los individuos determinarse como integrantes de una comunidad y al mismo tiempo, que cada grupo pueda diferenciarse de otros colectivos o incluso de la sociedad mayoritaria.

Palabras clave: Diversidad cultural, comunidades indígenas, derecho a la identidad cultural, integridad cultural.

ABSTRACT: This paper explains the legal nature of the right to cultural identity and its importance as a principle of interpretation that promote the debate on the scope and the understanding that fundamental rights must be based on the cultural context of indigenous groups. In addition, it is established that any State committed to cultural diversity should consider as a legitimate aim for democracy, the preservation of indigenous communities through the recognition of their cultural integrity as a fundamental right. Considering that preservation of culture is essential for the indigenous communities' survival as it serves as an agent of auto assignment that allow individuals to be identified as members of a community and at the same time, each group may

1 Licenciado en Derecho por la Facultad de Derecho de la Universidad Nacional Autónoma de México. Profesor de la asignatura Sistema Internacional de Derechos Humanos en la misma Facultad. 
differentiate itself from other groups or even of the majority society.

KEY WORDS: Cultural diversity, indigenous people rights, right to cultural identity, cultural integrity.

Sumario. I. Introducción; II. La diversidad cultural: el planteamiento del debate; III. Las comunidades indígenas como sujetos de derecho; IV. El Derecho a la identidad cultural; V. Consideraciones finales: elementos para el reconocimiento del derecho a la integridad cultural.

\section{INTRODUCCIÓN}

erivado de la falta de comprensión e indiferencia sobre su forma particular de concebir el mundo, las comunidades indígenas, especialmente en América Latina, han enfrentado múltiples adversidades para su supervivencia, desde prácticas de exterminio y erradicación hasta políticas de asimilación, integración y segregación que buscan la desaparición paulatina de sus especificidades culturales.

El derecho internacional ha intentado revertir esta situación. Sin embargo, la fuerte influencia del pensamiento liberal clásico en el proceso de reconocimiento de los derechos fundamentales y sus garantías es el principal obstáculo para responder a las demandas de las comunidades indígenas, puesto que coloca la preservación de la cosmovisión indígena en una posición de incompatibilidad con la protección de los derechos humanos.

En este contexto, el objetivo central de este estudio es aportar elementos y herramientas teóricas para la configuración del derecho a la integridad cultural de las comunidades indígenas, cuyo reconocimiento se enmarca, principalmente, en el debate existente sobre la preservación de la diversidad cultural y la protección de los derechos de las comunidades indígenas.

En este sentido, este artículo se inscribe en la necesidad de replantear la concepción del individuo y el principio de igualdad que 
surge de la teoría liberal clásica a fin de reconocer a las comunidades indígenas como sujetos de derechos capaces de reclamar por sí mismos los perjuicios que sufren como colectivo. Para lograr lo anterior, se propone comprender el derecho a la identidad cultural como una herramienta de interpretación de los derechos humanos desde el contexto cultural de las comunidades indígenas.

\section{La diversidad cultural: el planteamiento del debate}

Durante los últimos años, el proceso de reivindicación de los derechos de comunidades indígenas a partir de su reconocimiento como entes poseedores de una cultura e identidad claramente diferenciada de la cultura mayoritaria ha sido parte fundamental en las reflexiones teóricas sobre los retos que plantea la diversidad cultural. ${ }^{2}$

Hasta antes de la Segunda Guerra Mundial, el concepto de diversidad cultural se centraba en afirmar la existencia de Estados con sociedades homogéneas capaces de interactuar "culturalmente" con otros Estados de la misma naturaleza; el Estado era concebido como una entidad unitaria productora e importadora de cultura. ${ }^{3}$ Sin embargo, la aparición de algunos grupos al interior de los Estados con culturas distintas a la dominante provocó que dicho concepto tuviera que abordarse de manera diferente.

Will Kymlicka -filósofo canadiense que plantea una defensa liberal de los derechos de las minorías- afirma que el surgimiento de tres grupos particulares que comenzaron a utilizar la reivindicación de sus diferencias culturales como medio para lograr el reconocimiento de sus derechos, fue lo que permitió cobrar conciencia de la existencia de sociedades o naciones diversas al interior de un

2 Véase Oficina en México del Alto Comisionado de las Naciones Unidas para los Derechos Humanos, El reconocimiento legal y vigencia de los sistemas normativos indígenas en México, OACNUDH, México, 2010, p. 23.

${ }^{3}$ Véase Karina Vargas, Diversidad Cultural: Revisión de conceptos y estrategias, Generalitat de Catalunya, España, 2008, p. 5. 
solo Estado: las minorías nacionales, migrantes y las comunidades indígenas. ${ }^{4}$

Durante el siglo XX, el creciente reconocimiento del fenómeno de la diversidad cultural desembocó en la aprobación de la Declaración Universal sobre la Diversidad Cultural. ${ }^{5}$ Se trata de un instrumento que busca consolidar el compromiso por parte de la comunidad internacional en favor de "la fecunda diversidad de las culturas" en un espíritu de diálogo y apertura, tomando en cuenta los riesgos sociales que aparecen al construir una sociedad homogénea y desde una concepción universalista. ${ }^{6}$ En particular, esta Declaración plantea el concepto de la diversidad cultural como la multiplicidad de formas en que se expresan las culturas de los grupos y sociedades, que cuando se manifiesta, enriquece y transmite el patrimonio cultural de la humanidad. ${ }^{7}$

Hoy en día, la diversidad cultural ha sido entendida como un hecho que existe en, y en ocasiones preexiste a, los Estados; y como un concepto que se refiere a la multiplicidad de formas en que se expresan las diversas culturas de ciertas comunidades que suelen colocarse como grupos minoritarios en relación con el conjunto de personas que integran a la sociedad cultural mayoritaria o hegemónica. ${ }^{8}$

La diversidad cultural va más allá de reconocer el valor de la multiplicidad de expresiones e identidades culturales. Para las

4 Véase Will Kymlicka, Ciudadanía multicultural, Colección Estado y sociedad, España, 1999, p. 343.

5 Véase UNESGO, Declaración Universal sobre la Diversidad Cultural, adoptada en la $31^{\circ}$ Sesión de la Conferencia General de la UNESCO, 2 de noviembre de 2001, París, Preámbulo.

${ }^{6}$ Véase La Diversidad Cultural (Marco Conceptual), Campaña nacional por la diversidad cultural de México, CIESAS, GONAPRED, UNESCO, México, 2010, p. 12.

7 Idem.

8 Véase Olga Lucía Molgano, "Identidad Cultural. Un concepto que evoluciona", Revista Ópera, no. 7, Universidad del Externado, Colombia, 2007, p, 69. 
democracias modernas implica el surgimiento de interrogantes y retos de carácter económico, social y político relacionados con los derechos de minorías culturales, tales como la conformación de la identidad de sociedades multiculturales o la integración al mercado de grupos con necesidades disímiles y con expectativas y necesidades variadas. ${ }^{9}$

Bajo este contexto, cobra importancia el concepto de multiculturalismo. A diferencia del término "diversidad cultural" que se entiende como el reconocimiento de hecho de las múltiples formas de diversidad presentes en las sociedades contemporáneas, el multiculturalismo es "el reconocimiento político de algunas de estas formas de diferencia en los marcos legales y normativos de las distintas naciones", ${ }^{10}$ es decir, el concepto de multiculturalismo refiere también a la "adopción de las estrategias y políticas para gobernar o administrar los problemas de la diversidad cultural en las que se ven envueltas las sociedades multiculturales", ${ }^{11}$ por ello se ha abordado desde diversos enfoques. ${ }^{12}$

Daniel Bonilla resalta lo paradójico que resulta que quienes se dedican a la teoría del derecho y a la filosofía política no hayan analizado profundamente los problemas relacionados con el multiculturalismo. ${ }^{13}$ En especial, porque el principal reto que enfrentan los Estados frente al mismo se relaciona con la extensión de los derechos humanos a las personas pertenecientes a minorías culturales. Mientras los derechos

9 Sebastián Kaufmann, "Multiculturalidad y ética del reconocimiento" en Revista Persona y Sociedad, Volumen XXV, núm. 1, Universidad Alberto Hurtado, Colombia, 2011, p. 76.

10 Diana Bocarejo, "Dos paradojas del multiculturalismo colombiano: la espacialización de la diferencia indígena y su aislamiento político" en Revista Colombiana de Antropología, Volumen 47, Colombia, 201 1, p. 99.

11 Idem.

12 Véase Mauricio Beuchot, Interculturalidady Derechos Humanos, Siglo XXI Editores, México, 2005, p. 13.

13 Véase Daniel Bonilla, La Constitución Multicultural, Nuevo Pensamiento Jurídico, Colombia, 2006, p. 23 
humanos están estructurados en torno al individuo, las minorías tienen a las comunidades como su referente principal. ${ }^{14}$

En este sentido, uno de los argumentos que sostiene la insuficiencia de los derechos humanos para responder a la exigencia de las comunidades se refleja en que la mayor parte de instrumentos internacionales que refieren a la protección de colectividades con determinada identidad o especificidad, tienen al individuo como el sujeto fundamental de tutela y no a las colectividades consideradas, en sí mismas, como sujetos de derechos. ${ }^{15}$

Por otra parte, en prácticamente todas las democracias liberales uno de los mecanismos para acomodar las diferencias culturales es la protección de los derechos civiles y políticos de los individuos, ${ }^{16}$ por ello para las minorías culturales, y en especial para los pueblos y comunidades indígenas, el concepto de derechos humanos representa un conflicto fundamental con su visión del mundo donde la persona no es tan importante como la colectividad. ${ }^{17}$

La comprensión de juristas y filósofos políticos respecto a estos problemas comenzó a cambiar a partir de la década de los 80 con la aparición de rigurosos estudios sobre la complejidad de las sociedades contemporáneas culturalmente diversas. ${ }^{18}$ Distintos académicos como Charles Taylor, Michael Sandel y James Tully iniciaron un debate para exigir el replanteamiento de las bases de nuestras sociedades construidas sobre las ideas liberales de la ilustración. ${ }^{19}$ Esta postura

14 Ibidem, p. 35.

15 Véase Oficina en México del Alto Comisionado de las Naciones Unidas para los Derechos Humanos, El reconocimiento legal y vigencia de los sistemas normativos indígenas en México, op.cit., p. 23.

16 Véase Ermanno Vitale, Liberalismo y multiculturalismo, Un desafio para el pensamiento democrático, Océano, México, 2004, p. 26.

17 Véase Daniel Bonilla, op. cit., p. 212.

18 Véase Roberto Gargarella, Las teorías de la justicia después de Rawls. Un breve manual de filosofía política, Colección Estado y Sociedad, España, 1999, p. 125.

19 Véase Ronald Dworkin, La Comunidad Liberal, Nuevo Pensamiento Furídico, Colombia, 2004, p. 29. 
que propone, entre otras cosas, un replanteamiento sobre el papel del individuo dentro de su comunidad se denomina comunitarismo. ${ }^{20}$

Algunos de estos autores afirman que el multiculturalismo muestra que el pensamiento liberal excluye otras culturas. Principalmente, impugnan la concepción de derechos humanos universales, al denunciar la manera en que su pretendida universalidad silencia "otras miradas y voces diferentes a la racionalidad occidental liberal". ${ }^{21}$

El comunitarismo - en contraposición a las teorías liberales que basan su discurso en la persona como desvinculada de su contexto social-considera que el individuo es intrínsecamente relativo a la comunidad cultural en la que habita. ${ }^{22}$ Desde esta perspectiva, su comprensión se forma gracias a las particularidades y nexos que comparte con el grupo al cual pertenece, de tal suerte que, las personas se encuentran condicionadas por las tradiciones y costumbres de su pueblo, debido a que los intereses, valores morales, ideales políticos y la formación cultural dependen del contexto histórico y social en que les tocó nacer. ${ }^{23}$

Si bien la teoría del comunitarismo ha sido objeto de diversas críticas asociadas a los peligros de dar una preferencia absoluta de la comunidad sobre la persona, lo cierto es que, por su fuerte contraposición al liberalismo, se ha convertido en la principal herramienta teórica de resistencia contra la homogeneización de culturas minoritarias, como los pueblos indígenas.

Como se explica a continuación, las exigencias de reconocimiento indígena nos colocan frente a la necesidad de configurar de un nuevo modelo, posiblemente con tendencia comunitaria, donde el Estado pueda garantizar que todas las formas de ver el mundo coexistan pacíficamente, incluso si estas son incompatibles con los presupuestos que el propio Estado ha elegido para garantizar la

20 Véase Roberto Gargarella, op. cit., p. 132.

21 Kaufmann, op. cit., p. 74.

22 Véase Sergio Pérez Barahona, op. cit., p. 67.

23 Véase Ermanno Vitale, op. cit., p. 26. 
convivencia y su democracia. ${ }^{24}$ En particular, frente a la dificultad para entender algunas culturas desde una óptica que se define como universal, el derecho a la identidad cultural cumple un papel esencial para lograr la compatibilidad del deber de preservar la convivencia pacífica y los valores fundamentales dentro del territorio de cada Estado con el reconocimiento de las necesidades particulares de las comunidades indígenas como grupos culturalmente distintos.

\section{LAS COMUNIDADES INDígenAS COMO SUJETOS DE DERECHO}

El debate sobre el reconocimiento de personas indígenas como sujetos de derechos inició en el siglo XVI con las controversias sobre el trato que debían dar los conquistadores a las y los habitantes de América. ${ }^{25}$ Desde la época de la conquista y durante toda la colonia, las personas indígenas fueron colocadas en una posición de inferioridad natural, eran comprendidas como seres incapaces de controlar su destino. ${ }^{26}$

Estas nociones de inferioridad e incapacidad indígena dieron origen a un modelo tutelar que justificó la expropiación de territorios, recursos naturales de los pueblos originarios y la explotación desmesurada de su mano de obra. En este período, los pueblos indígenas fueron objeto, en el mejor de los casos, de políticas asistencia-

24 Véase Stuart Hall, Civil Society, Editorial Soundings, primera edición, Estados Unidos, 2001, p. 582.

25 En el año de 1550, Fray Bartolomé de las Casas y el jurista español Juan Ginés de Sepúlveda sostuvieron varios debates públicos donde Sepúlveda defendía el derecho de España, como nación civilizada, a someter por las armas a los "salvajes"; Fray Bartolomé sostenía una concepción de las personas indígenas como "seres racionales, libres de proyectar su propia vida". Véase. Emilio García, "Bartolomé de las Casas y los Derechos Humanos" en Los Derechos Humanos en su origen, Editorial San Esteban, España, 2009, p. 81-114.

26 Véase Raquel Fajardo, "El horizonte del constitucionalismo pluralista: del multiculturalismo a la descolonización”, Rodríguez César Garavito, El derecho en América Latina, Un mapa para el pensamiento jurídico del siglo XXI, Editorial Siglo XXI, Primera Edición, Argentina, 2011, p. 110. 
les por parte de sociedades particulares de beneficencia o misiones religiosas. ${ }^{27}$

En el siglo XIX, y contrario a lo que podría esperarse, la aparición de los movimientos de independencia en toda América significaron solo un reconocimiento formal de la igualdad de los indígenas respecto los demás habitantes. ${ }^{28}$ En Latinoamérica surgió un modelo de Estado nación construido bajo la idea de una sociedad homogénea, compuesta de individuos sometidos a un solo régimen jurídico y por lo mismo con iguales derechos para todos, lo que tuvo como consecuencia la omisión de consideraciones específicas y diferenciadas para las poblaciones indígenas: ${ }^{29}$ todas las tierras fueron sometidas a las normas del derecho común y civil que privilegiaba las formas privadas de propiedad, sin embargo, las personas indígenas, en su gran mayoría, carecían de los recursos y el conocimiento para inscribir y regularizar sus territorios ancestrales, siendo así desplazados y despojados de ellas. ${ }^{30}$

En síntesis, el colonialismo practicado por el imperio español se siguió practicando por los criollos y además, se consolidó en una política indigenista oficial, desarrollada por los mestizos y los grupos gobernantes identificados como los descendientes legítimos de los colonizadores españoles que buscaba que estas poblaciones se asimilaran a la cultura nacional. ${ }^{31}$

27 Véase Mikel Berraondo, Manual de los Pueblos indígenas y Derechos Humanos. Instituto de Derechos Humanos, Universidad de Deusto, España, 2006., p. 14.

28 Véase José Aylwin, El acceso de los indígenas a la tierra en los ordenamientos jurídicos de América Latina: un estudio de casos, Unidad de Desarrollo Agrícola, GEPAL, Chile, 2002, p. 18.

29 Véase Gletus Gregor, Pueblos Indígenas y derechos constitucionales en América Latina: un panorama. Editorial ABYA YALA, $2^{\circ}$ Edición, Bolivia, 2003, p, 451.

зо Véase El acceso de los indígenas a la tierra en los ordenamientos jurídicos de América Latina: un estudio de casos, Unidad de Desarrollo Agrícola, CEPAL, Chile, 2002, p. 13.

31 Véase James Tully, The Struggles of Indigenous Peoples for and of freedom en Political Theory and the rights of indigenous people, Cambridge University Press, United Kingdom, 2000, p. 37. 
El fracaso de las políticas de asimilación llegaría en el siglo XX con el surgimiento de la "conciencia indígena" que comenzó a evidenciar algunas fallas de origen del Estado-nación que la "élite mestiza" había venido construyendo. Al respecto, Rodolfo Stavenhagen relata que durante la década de 1960 se consolidó una nueva generación de hombres y mujeres indígenas educados en los modos que las sociedades occidentales les habían impuesto, quienes comenzaron a impulsar una creciente atención a las demandas de sus comunidades basadas en la diferencia histórica de sus culturas, de sus instituciones políticas y en sus derechos territoriales. ${ }^{32}$

Esta generación de personas fundó las primeras organizaciones indígenas, las cuales son consideradas como causa y efecto de las transformaciones sucedidas en la esfera pública en relación con el reconocimiento de los derechos de los pueblos indígenas ${ }^{33}$ ya que comenzaron a participar activamente en discusiones de derecho internacional y derechos humanos de los pueblos indígenas. ${ }^{34}$

Hasta ese entonces, los pueblos indígenas no figuraban en el derecho internacional y no tenían tratamiento específico en los organismos internacionales de derechos humanos sino que se les clasificaba como minorías y por tanto, se les otorgaban derechos de las minorías ${ }^{35}$ que no correspondían con la situación y problemáticas que estaban viviendo.

El primer acercamiento a los derechos de pueblos indígenas ocurrió en el año de 1953 cuando la Organización Internacional

32 Véase S. James Anaya, "Indigenous Peoples" in International Law, Oxford University Press, New York NY, 1996, p. 42.

${ }_{3}$ Véase Rodolfo Stavenhagen, "Derechos indígenas y derechos culturales de los pueblos indígenas", Revista Culturas populares e indigenas, s/n. 2004, p. 181.

34 Véase Ángela Santamaría, Derechos Humanos en América Latina. Mundialización y circulación internacional del conocimiento experto jurídico, Centro de Estudios Políticos e Internacionales, Editorial Universidad del Rosario, Colombia, 2008, p. 87.

35 Véase Anne Sophie Berche, Pueblos Indígenas y DESC: una lectura intercultural, Colección Textos de aquí y ahora, primera Edición, Editorial ILSA, Colombia, 2006, p. 49. 
del Trabajo comenzó a investigar la discriminación y explotación en el ámbito laboral de las personas de origen indígena, ${ }^{36}$ misma que concluiría en 1957 con la adopción del Convenio número 107 "Relativo a la protección e integración de las poblaciones indígenas y de otras poblaciones tribales y semitribales en los países independientes". ${ }^{37}$

El enfoque de ese Convenio era facilitar la integración de las personas indígenas en el mercado laboral a través de la eliminación de la discriminación y de la mejora de la formación profesional. ${ }^{38}$ No obstante, la perspectiva desde la que fue planteado reforzaba y defendía abiertamente la noción de la superioridad natural del occidente sobre las personas indígenas. ${ }^{39}$ Particularmente, este instrumento consideraba que entre las labores de los Estados Parte estaba integrar debidamente a las personas indígenas a la sociedad civilizada. Así, en su artículo $2^{\circ}$ señala que "incumbirá principalmente a los gobiernos desarrollar programas coordinados y sistemáticos con miras a la protección de las poblaciones en cuestión y a su integración progresiva en la vida de sus respectivos países". ${ }^{40}$

A pesar de que la concepción de las comunidades indígenas fue planteada en términos de erradicación y asimilación de patrones, el Convenio núm. 107 de la OIT logró colocar en la agenda internacional la discusión sobre los derechos indígenas y reconocer como una

36 Véase Asborn Eide, "Los pueblos indígenas, el Grupo de Trabajo sobre Poblaciones Indígenas y la adopción de la Declaración de la ONU sobre los Derechos de los Pueblos Indígenas" en El Desafio de la Declaración. Historia y futuro de la declaración de la ONU sobre pueblos indígenas. Dinamarca, 2010.

37 OIT, Convenio número 107 Relativo a la Protección e Integración de las Poblaciones Indígenas y de otras Poblaciones Tribales y Semitribales en los países independientes, Organización Internacional del Trabajo, Ginebra, 1957.

38 Véase Asborn Eide, op. cit., p.13.

39 Véase Anne Sophie Berche, op. cit., p. 49.

40 OIT, Convenio número 107 Relativo a la protección e integración de las poblaciones indígenas y de otras poblaciones tribal es y semitribales en los países independientes, Organización Internacional del Trabajo, Ginebra, 1957. Artículo, 2. 
causa subyacente de la vulnerabilidad de estos pueblos la generalizada y sistemática privación de sus tierras y territorios tradicionales. ${ }^{41}$

Ya en la década de los ochenta, el empuje del movimiento indígena en relación con el reconocimiento a su autonomía y libre determinación tornó insostenible la visión de integración y paternalismo del derecho internacional. ${ }^{42}$ En 1982, el Consejo Económico y Social de la onu autorizó a la Comisión de Derechos Humanos la creación del Grupo de Trabajo de Poblaciones Indígenas, que por años fue el principal foro que reunió a representantes de organismos internacionales, expertos y organizaciones indígenas. ${ }^{43}$

Simultáneamente, la OIT inició una revisión de su Convenio 107 basándose en la nueva perspectiva de una mayor autonomía para los pueblos indígenas, el reconocimiento de su control colectivo sobre la tierra y los recursos naturales. La revisión de este Convenio devino en la necesidad de elaborar un nuevo instrumento internacional: el Convenio 169 de la OIT sobre Pueblos Indígenas y Tribales adoptado en $1989 .{ }^{44}$

En la actualidad, el Convenio 169 es el único instrumento jurídico vinculante sobre derechos de los pueblos indígenas y su adopción se considera un salto cualitativo en tanto se les reconoce plenamente como sujetos de derechos. ${ }^{45}$ Asimismo, es atípico porque, a diferencia de otros convenios de la OIT, involucró la participación de actores no gubernamentales distintos de las orga-

41 Véase Asborn Eide, op. cit., p.13.

42 Véase Mikel Berraondo, op. cit., p. 21.

43 Véase ONU, Grupo de Trabajo sobre Poblaciones Indígenas, aprobado en su resolución E/RES/1982/34, Ginebra, 1982.

44 Véase ONU, Declaración de las Naciones Unidas sobre los Derechos de los Pueblos Indígenas. Sexagésimo primer período de sesiones, resolución aprobada por la Asamblea General en su resolución A/RES/61/295, Ginebra, 2000.

45 Véase Anne Sophie Berche, op. cit., p. 41. 
nizaciones de trabajadores o empleadores, es decir, las organizaciones indígenas. ${ }^{46}$

En el año 2006, se adoptó la Declaración de la ONU sobre los Derechos de los Pueblos Indígenas. A la fecha es considerado el instrumento internacional más completo sobre los derechos de los pueblos indígenas pues reafirma que poseen todos los derechos humanos reconocidos en el derecho internacional y reconoce que son titulares de derechos colectivos indispensables para su existencia, bienestar y desarrollo integral como pueblos. ${ }^{47}$

Desde luego, vale la pena mencionar que el proceso internacional de reconocimiento de los pueblos indígenas también ocasionó efectos a nivel nacional y regional que culminaría en un proceso de constitucionalización de su derechos en distintos países de América Latina, ${ }^{48}$ mismo que es considerado por Mauricio García Villegas como uno de los fenómenos socio-jurídicos más trascendentales de la historia reciente de la región relacionado con las comunidades indígenas. ${ }^{49}$

En Ecuador, la Constitución de 1998 reconoció expresamente los derechos de los pueblos indígenas; ${ }^{50}$ en Venezuela, los derechos de los pueblos indígenas fueron incluidos en la Constitución de 1999; ${ }^{51}$

46 Véase Virginia Leary, La utilización del Convenio no. 169 de la OIT para proteger los Derechos de los Pueblos Indígenas, Colección Pueblos Indígenas y Derechos humanos, Instituto Interamericano de Derechos Humanos, Primera Edición, Costa Rica, 1999, p. 18.

47 Véase ONU, Declaración de las Naciones Unidas sobre los Derechos de los Pueblos Indígenas. Sexagésimo primer período de sesiones, aprobada por la Asamblea General, A/RES/61/295, Ginebra, 2006, Preámbulo.

48 Véase Ángela Santamaría, op. cit., p. 82.

49 Véase Mauricio García Villegas, Sociología crítica y del derecho, Editorial Fontamara, México, 2009, p. 289.

50 La nueva Constitución del Ecuador, adoptada por la Asamblea Constituyente en 2008 reconoce los derechos de pueblos y comunidades indígenas en su capítulo cuarto.

51 Constitución de la República Bolivariana de Venezuela, Capítulo VIII. 
en Colombia, se reformó la Constitución en 1991.52 En México, el movimiento indígena Zapatista - considerado el más prominente de la región- formuló como el punto central de su plataforma política e inmediata el reconocimiento constitucional de los derechos de los pueblos indígenas, ${ }^{53}$ mismo que se alcanzaría hasta el año de $2001 .{ }^{54}$

Otra aportación importante para el reconocimiento de los pueblos y comunidades indígenas como sujetos de derechos lo constituye la jurisprudencia de la Corte Interamericana de Derechos Humanos, ya que ésta ha desarrollado algunos derechos específicos de los diversos instrumentos internacionales pertenecientes al corpus juris de derecho internacional de los derechos humanos de pueblos indígenas.

A través de este proceso, las comunidades indígenas dejaron de ser solamente una simple sumatoria de sujetos individuales pues fueron reconocidos como sujetos colectivos de derechos fundamentales. ${ }^{55}$ Sin embargo, el hecho de que los reclamos indígenas obtuvieran una ubicación dentro del universo jurídico devino en la

52 Constitución Política de Colombia, artículo 68.

53 En el marco del diálogo celebrado entre el EZLN y el gobierno federal para lograr un Acuerdo de Concordia y Pacificación con Justicia y Dignidad, celebrado en la sede de San Andrés, Chiapas, destaca el pronunciamiento conjunto que enviaron a las instancias de debate y decisión nacional: "Este pronunciamiento contiene los principios y fundamentos necesarios para la construcción de un pacto social integrador de una nueva relación entre los pueblos indígenas, la sociedad y el Estado (...) El establecimiento de la nueva relación entre los pueblos indígenas y el Estado, tiene como un punto de partida necesario la edificación de un nuevo marco jurídico nacional y en las entidades federativas. El gobierno federal asume el compromiso de impulsar, entre otras cosas, el reconocimiento en la Constitución Política nacional de demandas indígenas".

54 Como consecuencia, principalmente, de la lucha zapatista el 14 de agosto de 2001 se publicaría la reforma más importante en materia de derechos indígenas en México. Véase Decreto por el que se aprueba el diverso por el que se adicionan un segundo y tercer párrafos al artículo $1^{\circ}$, se reforma el artículo $2^{\circ}$, se deroga el párrafo primero del artículo $4^{\circ}$; y se adicionan un sexto párrafo al artículo 18, y un último párrafo a la fracción tercera del artículo 115 de la Constitución Política de los Estados Unidos Mexicanos, Publicado en el Diario Oficial el 14-07-2001.

55 Véase Corte Constitucional de Colombia en sentencia T-601/11. 
necesidad de consolidar un esquema conceptual desde donde pudieran ser comprendidas sus demandas. ${ }^{56}$

En particular, frente al fenómeno del reconocimiento de las comunidades indígenas el modelo de derechos individuales se tornó insuficiente, máxime cuando el reconocimiento de las comunidades generaba tensiones con los valores del Estado liberal. En este marco, el derecho a la identidad cultural abre la posibilidad a aceptar que existen formas complejas de individualidad que no pueden ser eliminadas buscando la asimilación o pertenencia absoluta de todas las comunidades a un sólo grupo o cultura.

\section{EL DERECHO A LA IDENTIDAD CULTURAL}

\section{Fundamentos teóricos de la identidad Cultural}

En el seno del debate multicultural, se encuentra el problema de la construcción de la identidad, en el cual, mientras los sujetos reclaman el poder descubrir y expresar, sin injerencias externas su identidad desde un plano individual; las comunidades indígenas expresan la necesidad de defender y promover su identidad colectiva. ${ }^{57}$

La teoría liberal concibe a los sujetos como separados unos de otros y de su comunidad, lo cual repercute en la construcción de la identidad pues no se reconocen los profundos vínculos que unen a los individuos con su comunidad; además, se muestra un tipo de sujeto que posee una identidad individualizada, es decir, "que es particularmente mía, y que yo descubro en mí mismo". ${ }^{58}$

Desde luego, esta perspectiva individualista se opone abiertamente a la cosmovisión indígena, donde la identidad no se cons-

56 Véase Juan Manuel Salgado, Convenio 169 de la O.I.T. sobre Pueblos Indígenas. Su aplicación en el derecho interno argentino, Segunda Edición, Argentina, 2010, p. 32.

57 Véase Sebastián Kauffman, op, cit., p. 76.

58 Véase Rubén Benedicto, "Liberalismo y comunitarismo: un debate inacabado" en STVDIVM Revista de Humanidades, número 16, México, 2010, p. 119. 
truye desde el individuo, sino que se forma gracias a una dinámica continua de interrelaciones que permite a las personas definir su propio reconocimiento como indígenas. ${ }^{59}$

La teoría comunitaria plantea como alternativa la primacía de la comunidad, en la que la propia identidad no viene dada de forma particular, sino por la pertenencia a una colectividad. ${ }^{60}$ La propuesta del comunitarismo es que la identidad se encuentra profundamente marcada por nuestra pertenencia a ciertos grupos, ya que nacemos insertos en ciertas comunidades y prácticas sin las cuales dejaríamos de ser quienes somos, ${ }^{61}$ por lo cual, defiende la importancia que posee la comunidad en la configuración de la identidad personal. ${ }^{62}$

La construcción de la identidad indígena trasciende la esfera individual, puesto que las personas definen su identidad e incluso su pertenencia a determinado grupo desde la suma de todas aquellas actividades y elementos materiales, espirituales y culturales que comparten con otros individuos y que distinguen a su comunidad de cualquier otra. ${ }^{63}$ Por ello, la perspectiva comunitaria ofrece una alternativa bastante aceptada sobre la construcción de la identidad individual y al mismo tiempo reconoce la existencia de una dimensión colectiva de la identidad, que será relevante para la configuración de la identidad cultural de las comunidades indígenas.

En el contexto de los pueblos y comunidades indígenas, la identidad se construye gracias al conjunto de elementos culturales por el cual las personas y el propio grupo se definen, manifiestan y son reconocidos. Tales referencias culturales que las y los integrantes de una comunidad comparten y transmiten de una generación a otra,

59 Véase Karina Vargas, op, cit., p. 9.

60 Véase Rodrigo Juárez, "El concepto de ciudadanía en el comunitarismo" en Revista Mexicana de Derecho Constitucional, Núm. 23, julio-diciembre 2010, México, p. 49.

61 Véase Roberto Gargarella, Las teorías de la justicia después de Rawls. Un breve manual de filosofía política, Colección Estado y Sociedad, España, 1999, p. 43.

62 Véase Rubén Benedicto, op. cit., p, 212.

63 Véase Rodolfo Stavenhagen, op. cit., p. 179. 
dan origen a una identidad colectiva basada en la cultura, es decir, la identidad cultural.

En otras palabras, la noción de identidad cultural ${ }^{64}$ surge a partir de la conciencia y voluntad del grupo de preservar todos sus rasgos culturales, ${ }^{65}$ mismos que operan como un agente de diferenciación en la medida que son características que les hacen distintos a la sociedad "mayoritaria" o "hegemónica". ${ }^{66}$

Charles Taylor señala que la identidad puede ser definida, principalmente, en términos lingüísticos, pues el lenguaje ofrece significados que permiten a los individuos volverse inteligibles frente a ellos mismos y frente al resto de la comunidad. ${ }^{67}$ El lenguaje, además de servir para la determinación de cierta identidad individual, constituye un fenómeno social que solo se estructura y mantiene en contextos grupales o comunitarios, por lo que permiten a una comunidad la configuración de cierta identidad de naturaleza colectiva. ${ }^{68}$

Precisamente, es el caso de las comunidades y pueblos indígenas, quienes a partir de su historia, lengua, cultos, técnicas ancestrales, tradiciones artísticas, instituciones propias, regímenes jurídicos y de administración de justicia, territorios y hábitat y todos los elementos propios de su cultura configuran una identidad propia y colectiva. ${ }^{69}$

Previo a profundizar en la naturaleza jurídica del derecho a la identidad cultural, vale la pena acotar la necesidad de asumir una concepción de la cultura compatible con las comunidades indígenas,

64 Véase Osvaldo Ruíz Chiriboga, "El Derecho a la Identidad Cultural de los Pueblos Indígenas y las Minorías Culturales" en Boletín Mexicano de Derecho Comparado, número 118. UNAM -IIJ, p.2.

65 Véase Corte Constitucional Colombiana Sentencia T-282/11.

66 Corte Constitucional Colombiana Sentencias: T-380/ 93, SU-039/97, SU-510/98 y T-282/11.

67 Pérez Sergio Barahona, op. cit., p, 64.

68 Véase Andrés Mercado, "Charles Taylor: de la auto interpretación a la participación política” en Anuario Filosófico, número XXXVI, Universidad de Navarra, España, 2003, p. 442-445.

69 Véase Corte Constitucional Colombiana Sentencia T 349/96. 
es decir, en términos de una forma de vida particular de ser, ver y actuar en el mundo indispensable para su determinación, desarrollo e incluso para su propia existencia como colectivo. ${ }^{70}$

$\mathrm{Al}$ respecto, Stavenhagen pugna porque la cultura sea entendida en un sentido antropológico e inherente a los grupos humanos, no solo como un conjunto de expresiones humanas. Asimismo, afirma que los derechos humanos se inscriben hoy en día "en el marco del relativismo cultural y apuntan hacia la definición de derechos humanos colectivos". ${ }^{71}$ En tal entendido, y más allá de proteger una cultura universal o general, sostiene que cada grupo tiene derecho a mantener y desarrollar su propia cultura, sea cual fuere la forma en que se inserta o se relaciona con las demás culturas. ${ }^{72}$

\section{Naturaleza Jurídica del derecho a la identidad CULTURAL}

Es posible definir el derecho a la identidad cultural como el derecho de todo grupo étnico y de sus integrantes a pertenecer a una determinada cultura, ser reconocido como diferente, conservar su propia cultura y a no ser forzado a pertenecer a una cultura diferente o ser asimilado involuntariamente; ${ }^{73}$ lo que incluye, el derecho del individuo y de un grupo a definirse, a manifestarse y a participar en la vida colectiva de acuerdo a un conjunto particular de referencias culturales. $^{74}$

70 Véase Voto razonado del Juez Cançado Trindade, Corte IDH. Caso Comunidad Indígena Sawhoyamaxa vs. Paraguay. Fondo, Reparaciones y Costas. Sentencia de 29 de marzo de 2006. Serie C No. 146.

71 Stavenhagen, Rodolfo, op. cit., p. 177.

72 Ibid.

73 Véase Osvaldo Ruíz Chiriboga, op. cit., p.13.

74 Véase ONU, Consejo Económico y Social, Los derechos culturales, adoptada en la cuadragésima sesión, Resolución E/C.12/40/16, Ginebra, 2009. 
Así, se encuentra reconocido en algunos instrumentos internacionales como la Declaración de las Naciones Unidas sobre los Derechos de los Pueblos Indígenas (Artículo 33.1); $7^{75}$ la Convención sobre los Derechos del Niño (artículo 30); ${ }^{76}$ y el Proyecto de Declaración Americana sobre los Derechos de los Pueblos Indígenas (Artículo V). ${ }^{77}$

De igual manera, es reconocido en varias constituciones de América Latina y aunque no se encuentra explícitamente consagrado en la Convención Americana ha sido ampliamente desarrollado y cristalizado $^{78}$ por la jurisprudencia de la Corte Interamericana de Derechos Humanos. ${ }^{79}$

El derecho a la identidad cultural, de igual forma que otros derechos de las comunidades indígenas, tiene una naturaleza dual consistente en la interconexión entre derechos individuales y co-

75 ONU, Declaración de las Naciones Unidas sobre los Derechos de los Pueblos Indígenas. Sexagésimo primer período de sesiones, Resolución A/RES/61/295, aprobada por la Asamblea General, Ginebra, 2006.

76 ONU, Convención sobre los Derechos del Niño, Adoptada por la Asamblea General, resolución 44/25, Ginebra, 1990.

77 OEA, Proyecto de Declaración Americana sobre los Derechos de los Pueblos Indígenas, aprobado por la Comisión Interamericana de Derechos Humanos, en su sesión 1333a , EUA, 1997.

78 Véase Cançado Trindade, Trindade, "The right to cultural identity" in Multiculturalismo and international law, Edited by Sienho Yee and Jacques-Yvan Morin. Martinus Nijhoff Publisersh. EUA, 2009, p. 473.

79 Véase Corte IDH. Caso Comunidad Indígena Yakye Axa vs. Paraguay. Fondo Reparaciones y Costas. Sentencia 17 de junio de 2005. Serie C No. 125; Corte IDH. Caso Pueblo Indígena Kichwa de Sarayaku vs. Ecuador. Fondo y Reparaciones. Sentencia de 27 de junio de 2012. Serie G No. 245, párr., 217; Corte IDH. Caso Masacres de Río Negro vs. Guatemala. Excepción Preliminar, Fondo, Reparaciones y Costas. Sentencia de 4 de septiembre de 2012 Serie C No. 250., párr., 177; Corte IDH. Caso Bámaca Velásquez vs. Guatemala. Reparaciones y Costas. Sentencia de 22 de febrero de 2002. Serie C No. 91; Corte IDH. Caso López Álvarez vs. Honduras. Fondo, Reparaciones y Costas. Sentencia de 1 de febrero de 2006. Serie C No. 141. 
lectivos. ${ }^{80}$ Esto quiere decir que su titularidad no sólo recae en la comunidad como ente colectivo, sino también en sus integrantes puesto que otorga una protección tanto en una dimensión colectiva a la comunidad como sujeto de derechos y al mismo tiempo, a fin de preservar el derecho de esa colectividad, también reconoce como titular al individuo. ${ }^{81}$

Desde una perspectiva individual, la determinación de este derecho implica poseer conciencia que se comparten ciertas creaciones, instituciones y comportamientos colectivos con el grupo al cual se pertenece y que no se encuentran fuera del mismo. ${ }^{82}$ En una vertiente colectiva, se materializa en la medida en que las comunidades que no ostentan los valores culturales de la sociedad mayoritaria ${ }^{83}$ pueden ejercer sus derechos fundamentales de acuerdo con su propia cosmovisión y manera de ver el mundo. ${ }^{84}$

Por último, es importante recalcar que ambas vertientes son especialmente relevantes para la protección de los distintos subgrupos existentes en toda comunidad que requieren de cierta protección reforzada y diferenciada para preservar o incluso rechazar los rasgos culturales de su grupo (mujeres, jóvenes, personas con discapacidad). Por ejemplo, tratándose de niñas y niños indígenas se reconoce que, de acuerdo con su cosmovisión, requieren formarse y

80 Véase CIDH, Situación de los derechos humanos de las personas y pueblos indígenas en las Américas, Informe de Carlos M. Ayala Corao, Relator Especial sobre Derechos de Pueblos Indígenas 1996-1999, p.1.

81 Véase Corte Constitucional de Colombia en sentencia T-380/93.

82 Véase Corte Constitucional de Colombia en sentencia T-778/05; Corte Constitucional de Colombia en sentencia T-282/11.

83 Por ejemplo, en el caso López Álvarez vs. Honduras la Corte Interamericana reconoció el empleo de una lengua constituye un dato específico de la identidad cultural, pues se trataba de la lengua correspondiente a un grupo que constituye una minoría con presencia cultural propia en la sociedad nacional hondureña. Véase Corte IDH. Caso López Álvarez vs. Honduras. Fondo, Reparaciones y Costas. Sentencia de 1 de febrero de 2006. Serie C No. 141.

84 Véase Corte Constitucional de Colombia en sentencia T-380/93. 
crecer dentro de su entorno cultural, ya que poseen una identidad distintiva que los vincula con su tierra, cultura, religión, e idioma. ${ }^{85}$

3. LA IMPORTANCIA Y FUNCIÓN DEL DERECHO A LA IDENTIDAD CULTURAL EN EL MARCO DE UN EsTAdo MULTICULTURAL

La identidad cultural además de ser reconocida como derecho fundamental es un principio de interpretación que permite definir el alcance de todos los derechos de las comunidades indígenas bajo el entendimiento de que los sujetos protegidos tienen una cosmovisión distinta a la de la sociedad mayoritaria. ${ }^{86}$

La Corte Interamericana ha determinado que el respeto a este derecho, en sus distintas manifestaciones reconocidas dentro de la protección - y a la vez dentro de las limitaciones- que brinda la Convención, es fundamental para poder hacer efectivos los derechos de las comunidades indígenas. ${ }^{87}$

En el caso del Pueblo Indígena Kichwa de Sarayaku, ${ }^{88}$ la Corte IDH constató que el Estado de Ecuador había celebrado varios

85 Véase Corte IDH. Caso Masacres de Río Negro vs. Guatemala. Excepción Preliminar, Fondo, Reparaciones y Costas. Sentencia de 4 de septiembre de 2012 Serie C No. 250., párr. 177.

86 Véase Corte Constitucional de Colombia en sentencia T-465/12.

87 "En lo que respecta a la Convención Americana, el derecho a la identidad cultural no se encuentra establecido expresamente, pero ha sido reconocido a partir de una interpretación evolutiva del contenido de los derechos consagrados en los artículos 1.1 , 5, 11, 12, 13, 15, 16, 17, 18, 21, 23 y 24 del mismo, dependiendo de los hechos del caso concreto. Aunque debe puntualizarse que no siempre que se vulnere uno de dichos artículos se estaría afectando el derecho a la identidad cultural". Véase Voto Parcialmente Disidente del Juez A. Abre Burelli, Corte IDH. Caso Comunidad Indígena Yakye Axa vs, Paraguay. Fondo Reparaciones y Costas. Sentencia 17 de junio de 2005. Serie C No. 125.

88 El territorio del Pueblo Sarayaku se encuentra ubicado en la región amazónica del Ecuador, en el área del bosque tropical. Las personas indígenas de Sarayaku subsisten de la agricultura familiar colectiva, la caza, la pesca y la recolección dentro de su territorio de acuerdo con sus tradiciones y costumbres ancestrales. 
convenios con empresas transnacionales sobre el territorio de dicho pueblo sin obtener su consentimiento. Desde la cosmovisión del Pueblo Sarayaku, a diferencia de la concepción occidental de propiedad privada, el territorio está ligado a un conjunto de significados: la selva es viva y los elementos de la naturaleza tienen espíritus (supay), que se encuentran conectados entre sí y cuya presencia sacraliza los lugares. ${ }^{89}$

En tal entendido, la Corte Interamericana reconocería que su noción de propiedad forma parte de su identidad cultural como pueblo indígena, y a su vez, señalaría que el reconocimiento de dicho derecho es vía de interpretación transversal para concebir, respetar y garantizar el goce y ejercicio de los derechos humanos de los pueblos y comunidades indígenas protegidos por la Convención. Así, interpretando el derecho a la propiedad privada desde la propia identidad del pueblo Sarayaku, determinaría la obligación de los Estados de garantizar a los pueblos indígenas que sean debidamente consultados sobre asuntos que inciden o pueden incidir en su vida cultural y social, de acuerdo con sus valores, usos, costumbres y formas de organización. ${ }^{90}$

Entre otros de los derechos fundamentales de los cuales gozan las comunidades indígenas relacionados con la protección de su identidad cultural, se encuentra el derecho a la consulta previa y el derecho a una educación que respete y desarrolle su identidad

Las decisiones sobre temas de especial trascendencia para el Pueblo se toman en la tradicional Asamblea comunitaria, denominada Tayjasaruta. Además, se encuentra organizado bajo un Consejo de Gobierno integrado por líderes tradicionales de cada comunidad (kurakas o varayuks), autoridades comunitarias, ex dirigentes, mayores, sabios tradicionales (yachaks) y grupos de asesores y técnicos de la comunidad.

89 Véase Corte IDH. Caso Pueblo Indígena Kichwa de Sarayaku vs. Ecuador. Fondo y Reparaciones. Sentencia de 27 de junio de 2012. Serie C No. 245, párr. 200-219.

90 Véase Corte IDH. Caso Pueblo Indígena Kichwa de Sarayaku vs. Ecuador. Fondo y Reparaciones. Sentencia de 27 de junio de 2012. Serie C No. 245, párr. 217. 
(educación intercultural bilingüe) ${ }^{91}$ mismos que solo pueden ser entendidos "en función del grupo al que pertenecen". ${ }^{92}$

Simultáneamente, la idea que subyace en la protección del derecho a la identidad cultural es el reconocimiento de que el Estado no puede imponer ninguna perspectiva cultural sobre las personas, sino reconocer y acomodar todas las culturas que lo habitan. ${ }^{93}$ En el marco de sociedades multiculturales, si el Estado elige proteger solamente una de las perspectivas culturales estaría enviando el mensaje de que las perspectivas no favorecidas son menos valiosas, lo cual contribuiría al debilitamiento e incluso desaparición de las culturas no favorecidas. ${ }^{94}$

Ahora bien, Boaventura De Sousa Santos propone que, para trascender del pretendido universalismo de los derechos humanos y eventualmente alcanzar una noción mestiza de los mismos, es imperativo promover un diálogo intercultural en torno a la concepción de la dignidad humana. En este sentido, afirma que "una de las tareas más cruciales en la construcción de una concepción multicultural de los derechos humanos es elevar la conciencia de la incompletud cultural a su máximo posible". ${ }^{95}$

En mi opinión, el derecho a la identidad cultural plantea precisamente la posibilidad de establecer un diálogo intercultural capaz de

91 La EIB permite el mantenimiento, revitalización y desarrollo de las lenguas indígenas, y a su vez favorece la adquisición, fortalecimiento y consolidación de idioma español. Así, reconoce y atiende la diversidad cultural y lingüística de las comunidades indígenas mediante el respeto de las diferencias en el ámbito de la educación. Véase Secretaría de Educación Pública. Lineamientos Generales para la Educación Intercultural Bilingüe para las niñas y niños indígenas, Dirección General de Educación Indígena de la Subsecretaría de Educación Básica y Normal, México, 1999., p. 46

92 Véase Corte Constitucional de Colombia en sentencia T-116/11.

93 Véase Corte Constitucional de Colombia en Sentencia C-063/10.

94 Véase Bonilla, Daniel op. cit., p. 217.

95 Ibidem, p. 69. 
trazar estándares mínimos de tolerancia para proteger los diferentes sistemas de valores culturales que coexisten en el Estado.

$\mathrm{Al}$ respecto, la Corte Constitucional Colombiana ha desarrollado que solo el respeto a la autonomía de las comunidades indígenas hará posible su supervivencia cultural, por lo que será necesario que el intérprete al ponderar los intereses que puedan enfrentarse en un caso concreto atienda siempre a la regla de "la maximización de la autonomía de las comunidades indígenas". ${ }^{96}$

La maximización de la autonomía de las comunidades indígenas afirma que las restricciones a la cosmovisión indígena deben ser necesarias para proteger derechos de mayor jerarquía. Se trata de una regla que busca ponderar los valores del Estado liberal con el interés de la preservación de la diversidad étnica de la Nación. ${ }^{97}$

En este sentido, y bajo el entendido de que la supervivencia de las comunidades está sujeta a que puedan proyectar sus costumbres hacia el futuro, el Estado debe garantizar la preservación de todas las expresiones de la identidad cultural de una comunidad indígena, ya sea desde la posibilidad de educar a las y los niños en su propio idioma hasta poder juzgar a sus integrantes según sus tradiciones.

Hasta ahora, salvo en algunas excepciones, se reconoce que el incumplimiento de estas obligaciones genera afectaciones a los derechos individuales de personas indígenas, tales como a la integridad física o el derecho a la vida. Sin embargo, asegurar la congruencia del pleno reconocimiento de las comunidades indígenas en tanto sujetos de derechos implicaría aceptar la existencia de una integridad colectiva de las comunidades indígenas que tiene como base la configuración de su identidad cultural.

96 Véase Corte Constitucional Colombiana T-523/97.

97 En específico, implica que sólo serían admisibles las restricciones a la autonomía de las comunidades, cuando se cumplan las siguientes condiciones: "a. Que se trate de una medida necesaria para salvaguardar un interés de superior jerarquía; y b. Que se trate de la medida menos gravosa para la autonomía que se les reconoce a las comunidades étnicas". Véase Corte Constitucional Colombiana T-254 de 1994, T-349 de 1996 y SU-510 de 1998. 
iv. Consideraciones FinAles: Elementos PARA EL RECONOCIMIENTO DEL DERECHO A LA INTEGRIDAD CULTURAL

Las comunidades indígenas son auténticos sujetos colectivos de derechos, por lo que la protección de sus derechos e intereses no debe subsumirse a las personas que la integran. En tal medida, el hecho de que puedan sufrir afectaciones diferenciadas a la de los individuos implicaría reconocer no solo un derecho fundamental a conservar la integridad de sus culturas para sobrevivir, sino también la posibilidad de reclamar como colectivo los detrimentos en su integridad. Es decir, las personas indígenas no solo deberían gozar en condiciones de igualdad de los mismos derechos que la sociedad mayoritaria, sino que es esencial que se les reconozca la posibilidad como grupos de coexistir con la sociedad y otras culturas en términos del reconocimiento a su identidad cultural. Por ello, el hecho de que una comunidad sea directamente menoscabada en su integridad por la trasgresión a su cultura, exigiría también que se le otorgue la personalidad sustantiva para reclamar como detrimentos suyos los perjuicios o amenazas que tengan la virtualidad de extinguirla. ${ }^{98}$

\section{Conceptualización de la integridad cultural desde el} DERECHO A LA IDENTIDAD CULTURAL

Una conceptualización más amplia de la integridad, acorde con la cosmovisión indígena, requiere aceptar la identidad cultural como un elemento esencial para que las comunidades puedan ejercer sus derechos fundamentales de acuerdo con su propia manera de ver el mundo pues funciona como una vía de abordaje para lograr una interpretación de los derechos coherente con las demandas indígenas. ${ }^{99}$

\footnotetext{
98 Véase Corte Constitucional de Colombia Sentencia 143/2010.

99 Corte Constitucional de Colombia en sentencia T-380/93.
} 
Como he mencionado, la identidad cultural es el conjunto de elementos culturales por el cual las personas y el propio grupo se definen, manifiestan y son reconocidos. Su naturaleza como método de interpretación implica repensar los derechos desde la mirada indígena. Por ello, valdría la pena acotar que la diversidad en características entre las comunidades indígenas no debilitaría la configuración de la integridad cultural. Por el contrario, conduciría justamente a la comprensión de que como derecho requiere interpretaciones diferentes en diferentes entornos.

En este orden de ideas, y con el fin de demostrar los alcances de la identidad cultural, resultan ejemplificativos los casos de las comunidades indígenas Yakye Axa y Sawhoayamaxa vs. Paraguay, ${ }^{100}$ donde el Tribunal Interamericano tomó en consideración la significación especial de la propiedad comunal de las tierras ancestrales como un elemento de la identidad cultural indígena a fin de dotar un mayor alcance al derecho reconocido en artículo 21 de la CADH (Propiedad Privada) hasta entonces restringido a la protección de la propiedad privada en sentido estricto. En particular, el Tribunal Interamericano determinó que:

[...] los conceptos de propiedad y posesión en las comunidades indígenas pueden tener una significación colectiva, en el sentido de

100 Las comunidades indígenas Yakye Axa y Sawhoyamaxa habitaron desde hace varios siglos el Chaco Paraguayo, sin embargo, desde los años 30's sufrieron la transferencia de sus tierras a terceros que las fraccionaron y ocuparon su mano de obra en condiciones precarias. Con el transcurso del tiempo la comunidad Yakye Axa se vio forzada a asentarse al borde de una carretera, en donde vivió bajo extremas condiciones de pobreza, pues no podían acceder a la tierra que les pertenecía para cultivar o cazar. Por su parte los miembros de la comunidad Sawhoyamaxa se dispersaron en varios asentamientos ubicados también al costado de la carretera que une las localidades de Pozo Colorado y Concepción, en una situación similar a la de la comunidad Yakye Axa. Corte IDH. Caso Comunidad Indigena Yakye Axa vs. Paraguay. Interpretación de la Sentencia de Fondo, Reparaciones y Costas. Sentencia de 6 de febrero de 2006. Serie C No. 142; Corte IDH. Caso Comunidad Indígena Sawhoyamaxa vs. Paraguay. Fondo, Reparaciones y Costas. Sentencia de 29 de marzo de 2006. Serie C No. 146 
que la pertenencia de ésta "no se centra en un individuo sino en el grupo y su comunidad". Esta noción del dominio y de la posesión sobre las tierras no necesariamente corresponde a la concepción clásica de propiedad, pero merecen igual protección del artículo 21 de la Convención Americana. Desconocer las versiones específicas del derecho al uso y goce de los bienes, dadas por la cultura, usos, costumbres y creencias de cada pueblo, equivaldría a sostener que solo existe una forma de usar y disponer de los bienes, lo que a su vez significaría hacer ilusoria la protección del artículo 21 de la Convención para millones de personas.

En consecuencia, la estrecha vinculación de los pueblos indígenas con sus tierras tradicionales y los recursos naturales ligados a su cultura que ahí se encuentren, así como los elementos incorporales que se desprendan de ellos, deben ser salvaguardados por el artículo 21 de la Convención Americana. ${ }^{101}$

De esta forma, desde la identidad cultural, la determinación del alcance y contenido del derecho a la integridad implicaría reconocer la significación colectiva de la cultura como un elemento de supervivencia para el grupo, ya que los atentados o trasgresiones contra la misma no ocasionan los mismos perjuicios en el individuo y en el grupo.

Es decir, si bien la cultura proporciona al individuo la posibilidad de generar un sentido de pertenencia e identificación con una comunidad determinada, lo cierto es que para las comunidades indígenas constituye el sustrato de su subsistencia porque conjunta los elementos básicos que, en su totalidad, permiten mantener la cohesión como grupo social. En este sentido, si no se garantiza la posibilidad del grupo étnico a conservar libre de injerencias todo el conjunto de atributos por los que define, manifiesta y es reconocida su identidad cultural, es posible que se coloque en riesgo su propia

101 Corte IDH. Caso Comunidad Indigena Yakye Axa vs. Paraguay. Interpretación de la Sentencia de Fondo, Reparaciones y Costas. Sentencia de 6 de febrero de 2006. Serie C No. 142; Corte IDH. Caso Comunidad Indigena Sawhoyamaxa vs. Paraguay. Fondo, Reparaciones y Costas. Sentencia de 29 de marzo de 2006. Serie G No. 146 
existencia, mientras que para el individuo implicarían solamente trasgresiones a su posibilidad de autodefinirse.

Ahora bien, en las sentencias de los casos masacre Plan de Sánchez ${ }^{102}$ y masacre Río Negro vs. Guatemala, ${ }^{103}$ la Corte IDH brindaría elementos para un nuevo abordaje de la integridad en un sentido colectivo. En particular, porque se encontró frente a la necesidad de pronunciarse sobre las consecuencias que tuvieron diversos ataques militares para la supervivencia de la cultura maya en Guatemala.

En el caso masacre Plan de Sánchez, el Tribunal Interamericano comprobó todo un conjunto de agresiones dirigidas a erradicar a

102 Este caso se desarrolló en un contexto de guerra de destrucción y erradicación de comunidades indígenas mayas identificadas por el ejército de Guatemala como "enemigos internos", pues consideraba que constituían o podían constituir la base social de la guerrilla. En específico, el 18 de julio de 1982 en la comunidad Plan de Sánchez, compuesta por personas indígenas del pueblo maya, se cometió una matanza de doscientos ochenta y seis personas por parte de un comando armado constituido por el Ejército guatemalteco y paramilitares integrantes de las Patrullas de Autodefensa Civil., plan de Sánchez, fueron víctimas de masacres que además de las afectaciones individuales significaron la destrucción completa de sus comunidades, viviendas, ganado, cosechas y otros elementos de supervivencia, su cultura, el uso de sus propios símbolos culturales, sus instituciones sociales, económicas y políticas, sus valores y prácticas culturales y religiosas como comunidad indígena. Corte IDH. Caso Masacre Plan de Sánchez vs. Guatemala. Fondo. Sentencia de 29 de abril de 2004. Serie C No. 105, p. 11-13.

103 El caso versa sobre cinco masacres cometidas en contra de la comunidad indígena de Río Negro, que además de graves costos humanos, materiales, institucionales y morales, ocasionaron afectaciones particulares a la comunidad indígena por la desaparición de su cultura. En particular, el desplazamiento forzoso y posterior reasentamiento implicó la pérdida de la relación que la comunidad tenía con la naturaleza, de la celebración de las fiestas tradicionales ligadas a la agricultura y el agua, del contacto con sus principales lugares sagrados y cementerios, que eran referentes culturales de los ancestros y de la historia de su pueblo, de sus líderes y guías espirituales, así como de los elementos materiales para la producción artesanal y musical, y del idioma Maya Achí. Corte IDH. Caso Masacres de Río Negro vs. Guatemala. Excepción Preliminar, Fondo, Reparaciones y Costas. Sentencia de 4 de septiembre de 2012 Serie G No. 250., párr, 55-102. 
esta comunidad maya a través de la destrucción de las formas tradicionales de transmisión de su cultura.

La Corte Interamericana demostró que, en los quince años posteriores a la masacre de la comunidad maya Plan de Sánchez y como consecuencia de la represión por parte de autoridades, los familiares de las víctimas no habían podido celebrar el ritual de despedida de sus familiares conforme a sus costumbres; ${ }^{104}$ también que con la muerte de mujeres y personas adultas mayores -transmisores orales de la cultura maya- los conocimientos no pudieron ser transmitidos a las nuevas generaciones; y que la militarización a la que fueron sometidos los sobrevivientes de la masacre, especialmente los jóvenes, ocasionó la pérdida de la fe en las tradiciones de sus antepasados ${ }^{105}$ que incluso significó un proceso de asimilación que provocó que las afectaciones se extremaran "gravísimas", ya que fueron obligados a incorporarse a los agresores como si fueran integrantes de aquél grupo y no de su comunidad. ${ }^{106}$

Precisamente, teniendo en consideración que los perjuicios trascendían del plano individual, el Tribunal Interamericano determinaría medidas de reparación a favor de la comunidad:

[...] Dado el daño ocasionado tanto a los miembros de la comunidad de Plan de Sánchez como a los miembros de las comunidades de Chipuerta, Joya de Ramos, Raxjut, Volcanillo, Coxojabaj, Las Tunas, Las Minas, Las Ventanas, Ixchel, Chiac, Concul y Chichupac, por los hechos del presente caso, este Tribunal dispone que el Estado debe desarrollar en dichas comunidades, independientemente de las obras públicas del presupuesto nacional que se destinen para esa región o municipio, los siguientes programas: a) estudio y difusión de la cultura maya achí en las comunidades afectadas

104 Véase Corte IDH. Caso Masacre Plan de Sánchez vs. Guatemala. Reparaciones. Sentencia de 19 de noviembre 2004. Serie C No. 116., párr. 49-50.

105 Ibidem

106 Véase Voto Razonado Juez Sergio García Ramírez en el caso Masacre Plan de Sánchez vs. Guatemala. Reparaciones. Sentencia de 19 de noviembre 2004. Serie C No. $116 .$, párr.1-5. 
a través de la Academia de Lenguas Mayas de Guatemala u otra organización similar; b) mantenimiento y mejoras en el sistema de comunicación vial entre las indicadas comunidades y la cabecera municipal de Rabinal; c) sistema de alcantarillado y suministro de agua potable; d) dotación de personal docente capacitado en enseñanza intercultural y bilingüe en la educación primaria, secundaria y diversificada de dichas comunidades. ${ }^{107}$

Por otra parte, en la sentencia del caso Masacre de Río Negro vs. Guatemala la Corte Interamericana consideró que la relación especial de los pueblos indígenas con sus territorios ancestrales no solo es un elemento integrante de su cosmovisión y religiosidad, sino también de su integridad cultural:

Esta Corte ya ha señalado que la relación especial de los pueblos indígenas con sus territorios ancestrales no estriba solamente en que constituyen su principal medio de subsistencia, sino un elemento integrante de su cosmovisión, religiosidad y, por ende, de su identidad o integridad cultural, el cual es un derecho fundamental y de naturaleza colectiva de las comunidades indígenas, que debe ser respetado en una sociedad multicultural, pluralista y democrática, como la de Guatemala. ${ }^{108}$

Por consiguiente, al momento de pronunciarse sobre las reparaciones también añadiría medidas tendientes al rescate de la cultura maya Achí. Particularmente, en el párrafo 285, la Corte estableció que las condiciones de vida en la colonia de los familiares desplazados (Pacux) generaron un perjuicio a la integridad cultural de la comunidad de Río Negro que impactaron lesivamente en cosmovisión y cultura maya:

107 Corte IDH. Caso Masacre Plan de Sánchez vs. Guatemala. Reparaciones. Sentencia de 19 de noviembre 2004. Serie C No. 116., párr. 110.

108 Corte IDH. Caso Masacres de Río Negro vs. Guatemala. Excepción Preliminar, Fondo, Reparaciones y Costas. Sentencia de 4 de septiembre de 2012 Serie C No. 250., párr, 160. 1 [N. E. Las cursivas son del autor.] 
Como ha sido establecido en la presente Sentencia, la exhumación e identificación de las víctimas fallecidas forma parte del deber de investigar. Pero, asimismo, se indicó que esta obligación debe ser llevada a cabo ex officio por el Estado. En tal sentido, independientemente de las investigaciones y procesos judiciales abiertos o que en el futuro realice el Estado, subsiste la obligación de este de realizar, de oficio, una búsqueda efectiva del paradero de las víctimas de este caso desaparecidas forzadamente o presuntamente ejecutadas, ya que el derecho de sus familiares de conocer su paradero constituye una medida de reparación y, por lo tanto, una expectativa que el Estado debe satisfacer por sí mismo. La localización e identificación de las víctimas devela una verdad histórica que contribuye a cerrar el proceso de duelo de la comunidad maya Achi de Río Negro; aporta a la reconstrucción de su integridad cultural; enaltece la dignidad de las personas desaparecidas o presuntamente ejecutadas y la de sus familiares, quienes han luchado durante décadas por encontrar a sus seres queridos, y sienta un precedente para que violaciones graves, masivas y sistemáticas, como las ocurridas en este caso, no vuelvan a suceder. ${ }^{109}$

\section{C.1.4.2. Proyecto para el rescate de la cultura maya Achí}

285. En esta Sentencia (supra párrs. 160 a 162), la Corte estableció que las condiciones de vida en la colonia de Pacux han generado un perjuicio a la integridad cultural de la comunidad de Río Negro, impactando lesivamente la cosmovisión y cultura maya Achí, así como las posibilidades de sus habitantes de ejercer sus actividades laborales y prácticas espirituales tradicionales. En consecuencia, la Corte le ordena al Estado diseñar e implementar, dentro de un año contado a partir de la notificación de esta Sentencia, un programa para el rescate de la cultura maya achí. Para tal efecto, en el plazo de tres meses, el Estado, en consulta con las víctimas y sus representantes, deberá diseñar un cronograma con metas de corto y mediano alcance para dar total cumplimiento a esta medida dentro del plazo

109 Corte IDH. Caso Masacres de Rio Negro vs. Guatemala. Excepción Preliminar, Fondo, Reparaciones y Costas. Sentencia de 4 de septiembre de 2012 Serie C No. 250., párrs. 160 a 162. [N. E. Las cursivas son del autor.] 
establecido para ello. Dicho programa estará dirigido a rescatar, promocionar, divulgar y conservar los usos y costumbres ancestrales, basado en los valores, principios y filosofías del pueblo maya achí y, particularmente, de la comunidad de Río Negro. Dicho programa deberá generar un espacio para promover las expresiones artísticas, lingüísticas y culturales de la comunidad. El diseño y ejecución de este programa deberá contar con la participación activa de los miembros de la comunidad de Río Negro y sus representantes. ${ }^{110}$

En estas sentencias es posible dilucidar algunos puntos importantes para el reconocimiento de una concepción amplia de la integridad y su reconocimiento como un derecho fundamental, pues la Corte su pronuncia sobre las afectaciones diferenciadas que encaran las comunidades indígenas distintas a la de sus integrantes, y por ende, otorga reparaciones como colectivo.

Por último, otro avance importante para el posible reconocimiento de la integridad cultural como derecho fundamental se encuentra en el Proyecto de Declaración Americana sobre Derechos de los Pueblos Indígenas que entiende las formas tradicionales colectivas de control y uso de tierras, territorios, recursos, aguas y zonas costeras como condición necesaria para la supervivencia, organización social, desarrollo, bienestar individual y colectivo de las comunidades indígenas. Además, consagra la existencia de un vínculo entre la integridad cultural y patrimonio histórico y ancestral con la continuidad y supervivencia colectiva de las comunidades indígenas y del propio Estado: ${ }^{11}$

110 Corte IDH. Caso Masacres de Río Negro vs. Guatemala. Excepción Preliminar, Fondo, Reparaciones y Costas. Sentencia de 4 de septiembre de 2012 Serie C No. 250, párrs. 165.

111 Véase OEA, Documento comparativo de trabajo entre el proyecto original de Declaración Americana sobre los derechos de los pueblos indigenas y las propuestas de los Estados, Grupo de Trabajo encargado de elaborar el Proyecto de Declaración Americana sobre los Derechos de los Pueblos Indígenas, aprobado por el Consejo Permanente de la Organización de Estado Americanos en su resolución GT/DADIN/ doc.37/01, EUA, 2000. 
Artículo VII. Derecho a la integridad cultural

1.Los pueblos indígenas tienen derecho a su integridad cultural, y a su patrimonio histórico y arqueológico, que son importantes tanto para su supervivencia como para la identidad de sus miembros.

2. Los pueblos indígenas tienen derecho a restitución respecto a la propiedad integrante de dicho patrimonio de la que fueran despojados, o cuando ello no fuera posible, a la indemnización sobre bases no menos favorables que el estándar del derecho internacional.

3. Los Estados reconocen y respetan las formas de vida indígena, sus costumbres, tradiciones, formas de organización social, instituciones, prácticas, creencias, valores, vestimentas, y lenguas. ${ }^{112}$

\section{v. Conclusión}

En mi opinión, el reconocimiento del derecho a la integridad cultural estaría estrechamente asociado con la necesidad de repensar los derechos fundamentales desde la cosmovisión indígena y con su reconocimiento efectivo como sujetos de derechos.

Como se ha expuesto, la diversidad cultural va más allá de aceptar el valor de la multiplicidad de expresiones e identidades culturales presentes en las sociedades contemporáneas, implica el reconocimiento jurídico y político de cada uno de los grupos que se ostentan como distintos dentro del Estado.

En Colombia, por ejemplo, la Corte Constitucional considera que el reconocimiento del derecho a la integridad étnica y cultural de los pueblos deriva de la protección legítima que la Constitución colombiana extiende a la diversidad cultural y a la aceptación de formas diferentes de vida social cuyas manifestaciones y permanente reproducción cultural son imputables a las comunidades indí-

112 OEA, Proyecto de Declaración Americana sobre los Derechos de los Pueblos Indígenas. aprobado por la Comisión Interamericana de Derechos Humanos, durante su $95^{\circ}$ Período Ordinario de Sesiones, EUA, 1997. 
genas como sujetos colectivos autónomos. ${ }^{113}$ Por consiguiente, el reconocimiento de este derecho como un fin legítimo ha permitido al mismo Tribunal reinterpretar los derechos fundamentales desde la cosmovisión indígena bajo la idea de que estos grupos están en la posibilidad de entablar un verdadero diálogo intercultural con los valores liberales del Estado Constitucional. ${ }^{114}$

De este modo, el derecho a la integridad cultural debería entenderse, en principio, como el derecho de todo grupo étnico a conservar su cultura libre de injerencias o afectaciones por parte de terceros. Sin embargo, su reconocimiento también debería imponer obligaciones de carácter positivo para el Estado a fin de que se adopten medidas para revertir la situación histórica de opresión y asimilación en que las comunidades indígenas están inmersas.

En este sentido, todo Estado que asuma un compromiso consecuente con el multiculturalismo, debería reconocer como finalidad legítima la preservación y supervivencia de las comunidades indígenas como colectivo - en tanto enriquecen la vida de una sociedad y tienen algo importante que decir a otras culturas- a fin de adoptar medidas para remediar el debilitamiento que sufrieron para su supervivencia en el pasado; para su protección frente a riesgos continuos en su futuro; ${ }^{115}$ así como para lograr el reconocimiento de la integridad cultural como un derecho inherente a las comunidades como sujetos colectivos de derechos.

113 Véase Corte Constitucional de Colombia Sentencia 143/2010.

114 Véase Corte Constitucional de Colombia Sentencias T-380/937; T-652/98; T-143/2012.

115 En relación con los derechos indígenas, Will Kymlicka trata de defender una política de la diferencia, pero desde una base que se encuentra firmemente ubicada dentro de la teoría de la neutralidad liberal. Así, por ejemplo, no reconoce que para ciertas poblaciones mantener la integridad de la cultura puede requerir la asignación de recursos., por lo que, se considera que no integra las demandas reales hechas por los grupos en cuestión con respecto a su meta de supervivencia. Will Kymlicka, op. cit., p. 25. 
En consecuencia, el reconocimiento del derecho a la integridad cultural debería trascender de un plano meramente declarativo y plantearse como la posible superación de esta asimetría entre dos maneras distintas de ver el mundo y como una exigencia de reinterpretar los derechos fundamentales y sus garantías - a través de la identidad cultural indígena-. Para lo cual, se requiere su reconocimiento como un valor fundamental dentro de cualquier Estado Constitucional y Multicultural. 